\title{
Basra Petrol Sahasındaki Atık Toprak-Yağ Karışımının Doğal Radyonüklid İçeriği ve Radyolojik Tehlike Seviyeleri
}

\author{
İskender Akkurt ${ }^{*}$, Kadir Günoğlu ${ }^{2}$, Hadi Al-Baidhani ${ }^{1}$ \\ ${ }^{1}$ Süleyman Demirel Üniversitesi, Fen-Edebiyat Fakültesi, Fizik Bölümü, Isparta, Türkiye (ORCID: 0000-0002-5247-7850) \\ 2 Isparta Uygulamalı Bilimler Üniversitesi, Teknik Bilimler Meslek Yüksekokulu, Isparta, Türkiye (ORCID: 0000-0002-9008-9162)
}

(Illk Geliş Tarihi 18 Nisan 2020 ve Kabul Tarihi 6 Temmuz 2020)

(DOI: 10.31590/ejosat.722575)

\begin{abstract}
ATIF/REFERENCE: Akkurt, İ., Günoğlu, K. \& Al-Baidhani, H. (2020). Ağlayankaya plaj kumlarında doğal radyoaktivite düzeylerinin ve radyolojik tehlike indekslerinin değerlendirilmesi. Avrupa Bilim ve Teknoloji Dergisi, (19), 715-721.

$\ddot{\mathbf{O} z}$

Özellikle taş, toprak, kaya gibi çevresel örneklerin doğal yapılarında farklı miktarlarda doğal radyonüklidler bulunmaktadır. Bu çevresel örneklerin doğal radyoaktivite seviyelerinin belirlenmesi çevrenin korunması ve insan sağlığı açısından önemlidir. Bu çalışmada, Basra petrol sahasındaki atık olarak ortaya çıkan yağla karışmış olan toprak örneklerinde Uranyum-238, Toryum-232 ve potasyum-40 doğal radyonüklidlerin aktivite konsantrasyonları ölçülmüsstür. Bu ölçümler Süleyman Demirel Üniversitesi Fizik Bölümünde bulunan $\mathrm{NaI}(\mathrm{Tl})$ dedektörlü gama ışını spektrometresi kullanılarak yapılmıştır. Ölçülen aktivite konsantrasyonları kullanılarak, özellikle bu alanlarda çalışan işçilerin maruz kalacağı radyolojik tehlike seviyeleri belirlenmiştir. Elde edilen tüm sonuçlar tavsiye edilen limit değerler ile karşılaş̧ırılmıştır.
\end{abstract}

Anahtar Kelimeler: Doğal Radyoaktivite, Toprak, Petrol Sahası, Basra

\section{Natural radionuclide content and radiological hazard levels of waste soil-oil mixture in the Basra oil field}

\begin{abstract}
There are different amounts of natural radionuclides in the natural structures of environmental samples such as stone, soil and rock. Determining the natural radioactivity levels of these environmental samples is important for the protection of the environment and human health. In this study, the activity concentrations of Uranium-238, Thorium-232 and potassium-40 natural radionuclides were measured in soil samples mixed with oil that emerged as waste in the Basra oil field. These measurements were made using NaI (Tl) detector gamma ray spectrometry in Süleyman Demirel University Physics Department. Using the measured activity concentrations, the levels of radiological hazards to which especially workers working in these areas will be exposed were determined. All results obtained were compared with the recommended limit values.
\end{abstract}

Keywords: Natural Radioactivity, Soil, Oil Field, Basra.

\section{Giriş}

Dünya üzerindeki tüm canlılar doğal ve yapay kaynakların sebep olduğu bir radyasyona sürekli maruz kalmaktadır. Bu maruz kalınan radyasyonun \%86'sını kozmik ışınlar ve karasal radyasyon gibi doğal kaynaklar oluştururken, tıbbi, endüstriyel, tarımsal faaliyetler sonucunda oluşan yapay radyasyonun etkisi yaklaşık \%14 tür. İnsanların maruz kalmış oldukları doğal radyasyon kaynaklarından alınan yıllık ortalama etkin doz $2.4 \mathrm{mSv}$ 'dır. Maruz kalınan bu etkin doza en büyük katkı primordial radyonüklitlerden (potasyum-40, Uranyum-238 ve Toryum-232 serisi bozunum ürünleri) gelmektedir [1]. Dünyanın var oluşundan bu yana uzun ömürlü

\footnotetext{
* Sorumlu Yazar: Süleyman Demirel Üniversitesi, Fen-Edebiyat Fakültesi, Fizik Bölümü, Isparta, Türkiye, ORCID: 0000-0002-5247-7850, iskenderakkurt@sdu.edu.tr
} 
primordial radyonüklitler yana yaşamış olduğumuz çevredeki taş, kaya ve toprak gibi çevresel materyallerde bulunmaktadır ve bu radyonüklitler dışsal maruz kalmaya sebep olmaktadır. Özellikle zamanımızın çoğunu geçirmiş olduğumuz binaların yapımında kullanılan yapı malzemelerinden kaynaklanan radon gazı iç ışınlanmanın en önemli kaynağıdır. İnsan sağlığı üzerinde bu denli etkili olan doğal radyoaktivite dağılımı her bölgenin fiziki ve coğrafi yapısı, jeolojik yapısına ve belirli amaçlar için yapılan faaliyetlere bağlı olarak değişim göstermektedir[2].

Petrol çıkarma ve üretiminin yapıldığı sanayi alanlarında yürütülen faaliyet ve süreçlerin sonunda katı, sıvı veya çamur şeklinde çeşitli atıklar üretilir. Bu tür tesislerde üretilen atıklardan Doğal Olarak Oluşan Radyoaktif Malzeme (NORM) ile kontamine olması muhtemel tipik kalıntılar vardır. Teknolojik Olarak Geliştirilmiş Doğal Olarak Oluşan Radyoaktif Malzeme (TENORM) olarak adlandırılan doğal radyonüklitler, petrol işleme sonucunda ortaya çıkan bu kalıntılar içinde birikebilir [3]. TENORM petrol sahalarında kireç birikintileri, çamur ve su gibi atıklar petrol ve gaz çıkarma işlemleri sırasında ortaya çıkar.

Radyonüklitlerin konsantrasyonu ve dağılımı, çevresel radyoaktivitenin değerlendirilmesi ve izlenmesinde birçok bilimsel çalışmanın ana konusudur. Çevresel örneklerdeki radyonüklitlerin konsantrasyonu, doğal radyoaktivitenin kaynağını bulmak, çevresel etkileri belirlemek ve radyasyon risklerini değerlendirmek için önemlidir. Bu nedenle, dünyanın farklı bölgelerindeki birçok araştırmacı, çevresel materyallerdeki doğal radyoaktivite seviyelerinin belirlenmesi için çalışmalar gerçekleştirmiştir [4-8]. Ayrıca farklı petrol sahası türlerinin ${ }^{40} \mathrm{~K},{ }^{226} \mathrm{Ra}$ ve ${ }^{232} \mathrm{Th}$ aktivite konsantrasyonlarını incelemiştir [9-16].

$\mathrm{Bu}$ çalışmada, Basra-Irak'taki petrol alanındaki bazı toprak-yağ karışımı örneklerinde ${ }^{40} \mathrm{~K},{ }^{226} \mathrm{Ra}$ ve ${ }^{232} \mathrm{Th}$ doğal radyonüklitlerin aktivite konsantrasyonları ölçülmüştür. Ayrıca, radyolojik tehlikeleri değerlendirmek için, elde edilen aktivite konsantrasyonları kullanılarak radyum eşdeğeri aktivite $\left(\mathrm{Ra}_{\mathrm{eq}}\right)$, absorbe edilen doz oranı (D), yıllık etkili doz eşdeğeri (AEDE), iç ve dış tehlike indeksleri $\left(\mathrm{H}_{\mathrm{ex}}\right.$ ve $\left.\mathrm{H}_{\text {in }}\right)$ hesaplanmıştır.

\section{Materyal ve Metot}

\subsection{Numunelerin Toplanması ve Hazırlanması}

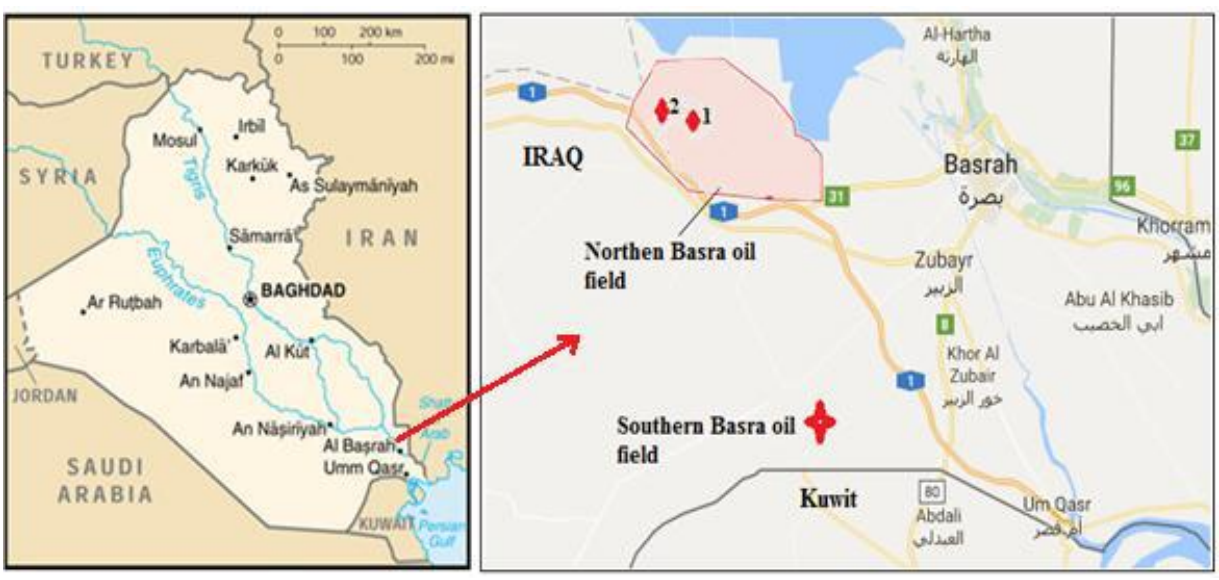

Şekil 1. Basra petrol sahalarl ve örnekleme noktalart

Basra'nın orta batısından Kuveyt'in kuzeyine kadar uzanan Basra petrol sahaları, $1.600 \mathrm{~km}^{2}{ }^{\prime}$ lik geniş bir alanı kapsamaktadır. Basra petrol sahaları Kuveyt'e yakın olan Kuzey Basra ve Güney Basra olmak üzere iki kısma ayrılmıştır (Şekil 1). Bu alanda kumtaşı katmanlarından dört kilometreye kadar derinliklerde çıkarılan yağ türü yüksek kaliteleriyle karakterize edilir ve yüksek geçirgenliğe ek olarak ortalama\% 20 gözenekliliğe sahiptir.

$\mathrm{Bu}$ çalışma kapsamında Basra petrol sahası bölgesindeki 2 farklı noktadan yağlı toprak örnekleri toplanmıştır (Şekil 1.). Toplanan yağlı toprak örneklerinin her biri yaklaşık $500 \mathrm{gm}$ ağırlığındadır. Yağlı toprak örnekleri $10 \mathrm{~cm}$ derinliğe kadar toplanmıştır. Tüm yağlı toprak örneklerinde, nemin tamamen çıkarılmasını sağlamak için 24 saat boyunca yaklaşık $110^{\circ} \mathrm{C}^{\prime}$ de bir firında kurutuldu. Yağlı toprak örnekleri öğütüldükten sonra çakıl taşlarını ve diğer makro safsızlıkları homojenleştirmek için $1 \mathrm{~mm}$ gözenekli bir elek ile elenmiştir. Homojenize yağlı toprak örnekleri standart $500 \mathrm{ml}$ hava geçirmez PVC plastik bir kaba konuldu. Kapaklar sıkıca kapatıldıktan sonra, radon gazlarının olası kaçışını önlemek için kapaklar vinil bantla sıkıca kapatıldı. Son olarak, ölçümden önce, ${ }^{238} \mathrm{U}\left({ }^{226} \mathrm{Ra}\right)$ ve ${ }^{232} \mathrm{Th}\left({ }^{228} \mathrm{Ra}\right)$ ve projenleri arasında radyoaktif dengeyi sağlamak için yağlı toprak örnekleri 4 haftalık bir süre boyunca saklandi.

\subsection{Gama Işını Spektrometresi}

Ölçüm için hazırlanan yağlı toprak numunelerindeki doğal radyonüklitlerin aktivite konsantrasyonları gama 1şını spektrometresi kullanılarak belirlenmiştir. $\mathrm{Bu}$ spektrometre sistemi, fotoçoğaltıcı tüplere bağlı talyum ile aktive edilmiş sodyum iyodür (NaI) sintilasyon kristali içerir. Ölçüm sisteminin geometrisini tasarlarken, arka plan radyasyonunun ölçümler üzerindeki etkilerini azaltmak için dedektör kurşun bloğa yerleştirilmiştir (Şekil 2.). 
Yağlı toprak örneklerinin doğal radyoaktivite ölçümlerine başlamadan önce, dedektör sisteminin enerji kalibrasyonu ve algılama verimliliği kalibrasyonu gibi bazı işlemler gereklidir. Enerji kalibrasyonu, gama 1şını enerjisi bilinen radyoaktif sezyum-137 (662 keV) ve kobalt-60 (1173 ve $1332 \mathrm{keV}$ ) kaynakları kullanılarak yapıldı.

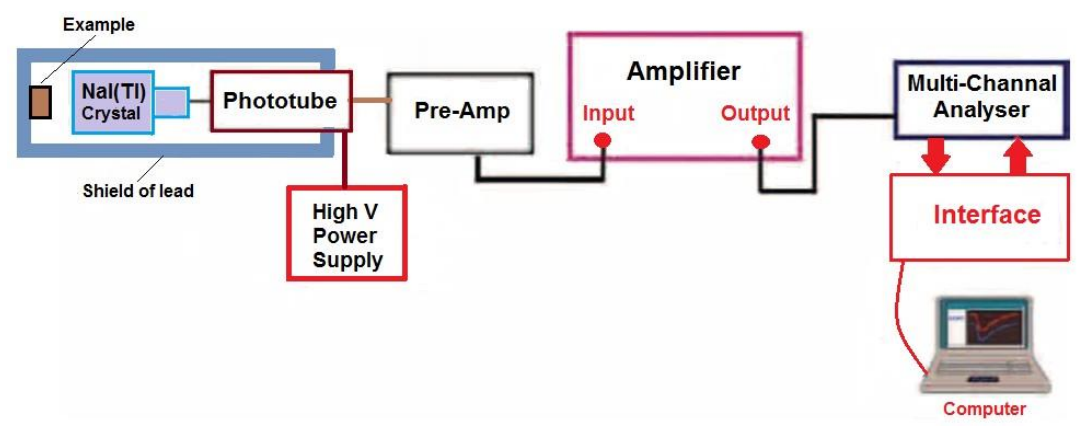

Şekil 2. Gama spektrometresi ve elektronik birimlerin şematik görünümü

Algılama verimliliği kalibrasyonu iki değişkene göre yapılmıştır. Bu değişkenlerden ilki, dedektör ve radyoaktif kaynak arasındaki mesafedir. Bu mesafe $0.5 \mathrm{~cm}$ olarak alınmıştır. İkinci değişken, farklı gama 1şını enerjileridir. Algılama verimliliği kalibrasyonu belirlenirken altı farklı gama ışını enerjisi kullanıldı. Bu değişkenlere bağlı olarak elde edilen algılama verimliliği kalibrasyon değerleri Şekil 3'te gösterilmiştir [17]. Şekil 3'te görülebileceği gibi, $\mathrm{R}^{2}$ değerleri 1'e yakın olduğu için verimlilik değerleri tutarlidır.

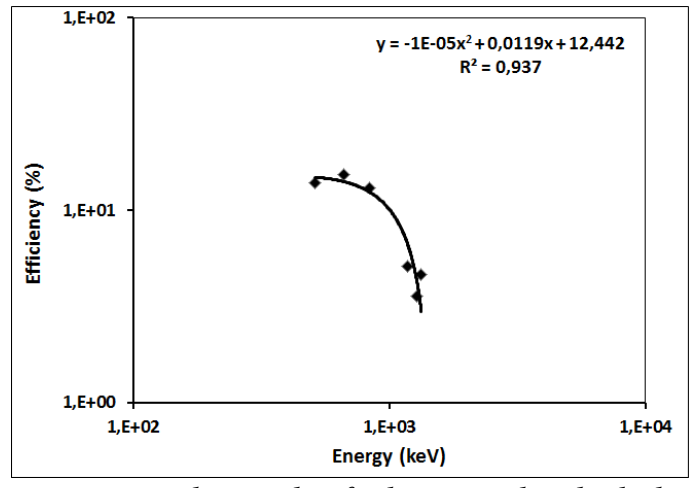

Şekil 3. Gama ışını enerjilerinin bir fonksiyonu olarak algılama verimliliği

Ölçümler sonucunda elde edilen spektrumların analizinde, spektrumların alanları MAESTRO32 bilgisayar yazılımı kullanılarak hesaplanmıştır. ${ }^{40} \mathrm{~K},{ }^{226} \mathrm{Ra}$ ve ${ }^{232} \mathrm{Th}$ doğal elementlerinin doğal radyoaktivite miktarı, doğal gama ışını spektrumunda sırasıyla 1461 , 1760 ve $2610 \mathrm{keV}$ gama ışını enerjilerinde fotopikler kullanılarak hesaplandı. [17].

${ }^{40} \mathrm{~K},{ }^{226} \mathrm{Ra}$ ve ${ }^{232} \mathrm{Th}$ doğal radyonüklitlerin aktiviteleri spektrum alanlarının yardımıyla aşağıdaki denklem kullanılarak hesaplanmıştır. [18].

$$
A(B q / k g)=\frac{N_{S}-N_{B}}{E_{\gamma} \cdot P_{\gamma} \cdot t \cdot M_{S}}
$$

Burada $\mathrm{N}_{\mathrm{S}}$ örnek için net fotopik alan, $\mathrm{N}_{\mathrm{B}}$ arka plan fotopik alan, $\mathrm{E}_{\gamma}$ gama ışını algılama verimliliği, $\mathrm{P}_{\gamma}$ gama 1şını emisyon olasılığı, $\mathrm{t}$ ölçüm süresi ve $\mathrm{M}_{\mathrm{S}}(\mathrm{kg})$ örneklerin kuru ağırllğını ifade etmektedir.

\section{Araştırma Sonuçları ve Tartışma}

\subsection{Aktivite Konsantrasyonları}

Basra-Irak'ta petrol sahasından toplanan yağlı toprak örneklerinde primordial radyonüklidler ${ }^{40} \mathrm{~K},{ }^{226} \mathrm{Ra}$ ve ${ }^{232} \mathrm{Th}$ 'in aktivite konsantrasyonları gama spektroskopisi kullanılarak ölçülmüsşür. ${ }^{40} \mathrm{~K},{ }^{226} \mathrm{Ra}$ ve ${ }^{232} \mathrm{Th}$ aktivite konsantrasyonları için Dünya ortalama değerleri sırasıyla 400, 35 ve $30 \mathrm{~Bq} / \mathrm{kg}$ 'dır [1]. Bu çalışmada deneysel olarak bulunan ${ }^{40} \mathrm{~K},{ }^{226} \mathrm{Ra}$ ve ${ }^{232} \mathrm{Th}$ aktivite konsantrasyonu değerleri, tüm yağlı toprak örneklerinde dünya ortalama değerlerinden daha yüksektir. ${ }^{40} \mathrm{~K},{ }^{226} \mathrm{Ra}$ ve ${ }^{232} \mathrm{Th}$ için ölçülen aktivite konsantrasyonu sonuçları şekil 4. de dünya ortalamasıyla birlikte gösterilmiştir. 


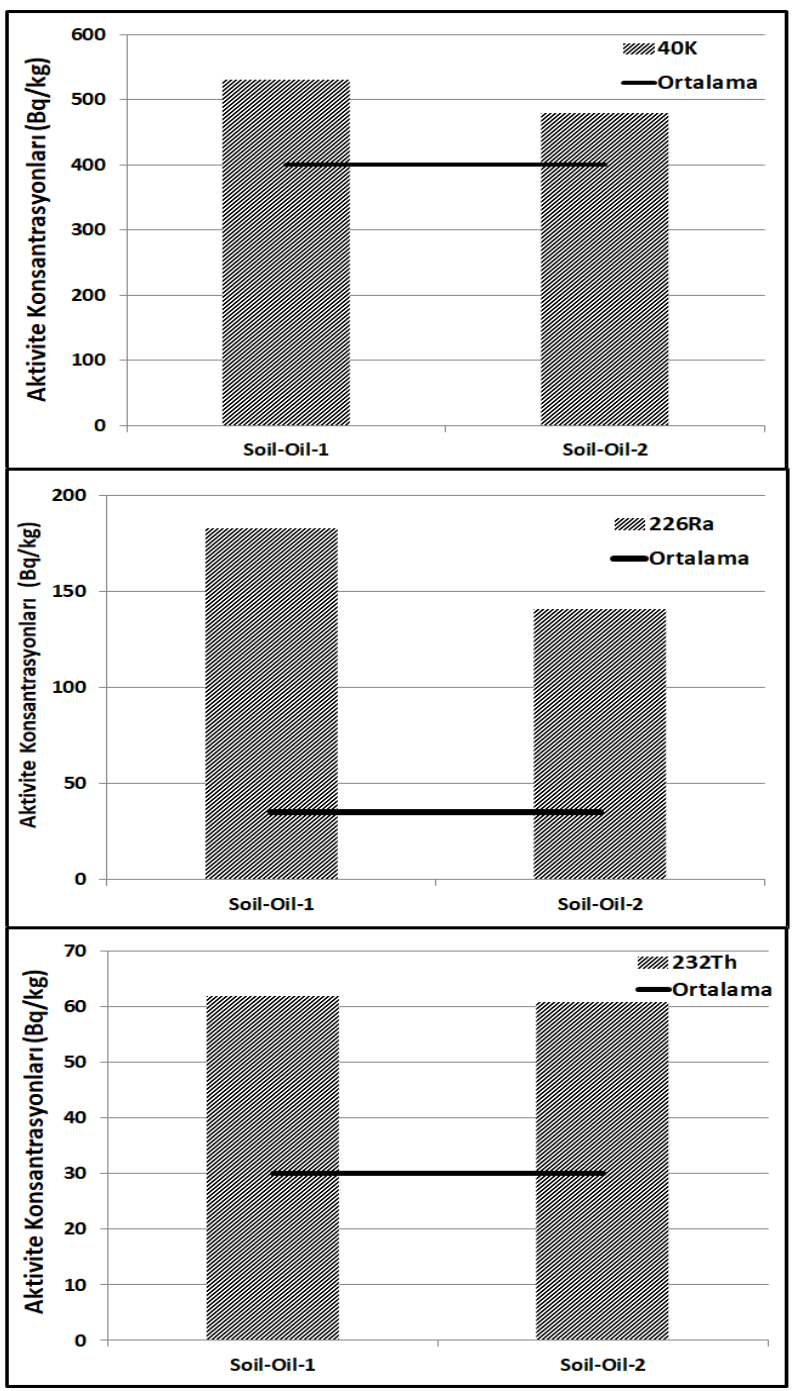

Şekil 4. ${ }^{40} \mathrm{~K},{ }^{226} \mathrm{Ra}$ and ${ }^{232} \mathrm{Th}$ radyonüklid aktivite konsantrasyonlarl

\subsection{Doz Ve Radyolojik Tehlike Etkilerinin Değerlendirilmesi}

Literatürde bu konuda yapılan çalışmalarda radyasyona maruz kalma veya ışınlamanın insanlar ve çevre üzerindeki etkilerinin değerlendirilmesinde aktivite konsantrasyonları kullanılarak farklı parametreler hesaplanmıştır. Bu parametreler radyasyonun etkilerini belirlemek için daha iyi ve daha güvenli sonuçlar elde etmek için kullanılır. Radyolojik parametreler için önerilen güvenlik limiti değerleri Tablo 1'de verilmiştir. Bu nedenle çalışmada yağlı toprak örnekleriyle ilişkili radyasyon tehlikelerini değerlendirmek için aşağıdaki doz ve radyolojik zarar parametreleri hesaplanmıştır.

Tablo 1. Aktivite konsantrasyonlarl ve radyolojik parametreler için önerilen ortalama ve limit değerleri

\begin{tabular}{|l|c|c|}
\hline Aktivite konsantrasyonu & Ortalama değer & Referans \\
\hline${ }^{40} \mathrm{~K}$ & $400 \mathrm{~Bq} / \mathrm{kg}$ & {$[1]$} \\
\hline${ }^{226} \mathrm{Ra}$ & $35 \mathrm{~Bq} / \mathrm{kg}$ & {$[1]$} \\
\hline${ }^{232} \mathrm{Th}$ & $30 \mathrm{~Bq} / \mathrm{kg}$ & {$[1]$} \\
\hline Absorbe Edilen Gama Doz Oranı $(\mathrm{D})$ & $59 \mathrm{nGy} / \mathrm{h}$ & {$[1]$} \\
\hline Yillık Etkin Doz Eşdeğeri (YEDE) & $0.46 \mathrm{mSv} / \mathrm{y}$ & {$[1]$} \\
\hline Radyolojik parametre & Limit değer & Referans \\
\hline Radyum Eşdeğer Aktivitesi $\left(\mathrm{Ra}_{\mathrm{eq}}\right)$ & $370 \mathrm{~Bq} / \mathrm{kg}$ & {$[19]$} \\
\hline Diş Zarar İndeksi $\left(\mathrm{H}_{\mathrm{ex}}\right)$ & $\leq 1$ & {$[1]$} \\
\hline İç Zarar İndeksi $\left(\mathrm{H}_{\text {in }}\right)$ & $\leq 1$ & {$[1]$} \\
\hline
\end{tabular}

\subsubsection{Absorbe Edilen Gama Doz Oranı (D)}

Absorbe edilen gama doz oranı (D), ${ }^{40} \mathrm{~K},{ }^{226} \mathrm{Ra}$ ve ${ }^{232} \mathrm{Th}$ doğal radyoaktif elementlerin dağılımına bağlı olarak dış karasal gama radyasyonunun neden olduğu yerin $1 \mathrm{~m}$ yukarısında havada emilen doz oranı olarak tanımlanmaktadır. Absorbe edilen gama doz oranını hesaplamak için, UNSCEAR2000 raporlarında belirtilen nGy / s cinsinden doz dönüşüm faktörleri kullanılır. Absorbe edilen gama doz oranı, bu doz dönüşüm faktörleri kullanılarak aşağıdaki denklem kullanılarak hesaplanır. [1]. 


$$
D(n G y / h)=0.0417 A_{K}+0.462 A_{R a}+0.604 A_{T h}
$$

Burada $A_{K}, A_{R a}$ ve $A_{\text {Th }}$ sırasıyla ${ }^{40} \mathrm{~K},{ }^{226} \mathrm{Ra}$ ve ${ }^{232} \mathrm{Th}$ aktivite konsantrasyonlarıdır. Çalışılan bölgedeki doğal radyonüklidlere bağlı emilen doz gama oranı değerleri Şekil 5 'te gösterilmiştir. Absorbe edilen gama doz oranı değerlerinin, önerilen güvenlik limiti $59 \mathrm{nGy}$ / s'den daha yüksek olduğu açıktır (Tablo 1.).

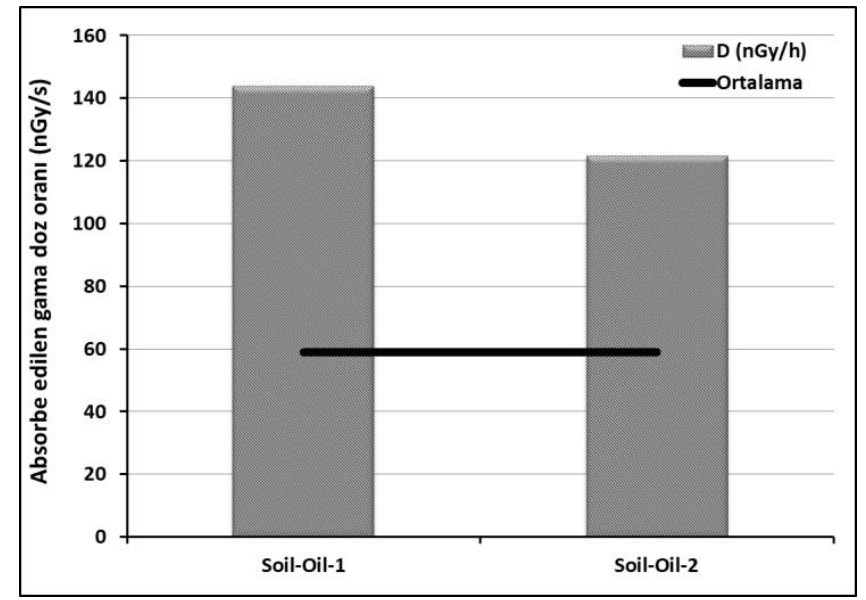

Şekil 5. Absorbe edilen gama doz oranı sonuçları

\subsubsection{Yıllık Etkin Doz Eşdeğeri (YEDE)}

Yukarıda hesaplanan absorbe edilen gama doz oranı ve dış doluluk faktörü kullanılarak yıllık etkin doz eşdeğerini (AEDE) hesaplamak mümkündür. UNSCEAR2000 raporlarında D için dönüşüm katsayısı $0.7 \mathrm{~Sv} /$ Gy olarak verilmiştir. Buna ek olarak, yetişkinlerin zamanlarının yaklaşık \%20'sini dışarıda geçirdiği varsayılarak bina dışı meşguliyet faktörü 0,2 olarak alınmıştır. Buna göre, YEDE (mSv / y) aşağıdaki formülle hesaplanmıştır [1].

$$
Y E D E(m S v / y)=D(n G y / h) * 8760 h * 0.2 * 0.7(S v / G y) * 10^{-6}
$$

Yıllık etkin doz eşdeğeri sonuçları Şekil 6'da gösterilmiştir. Şekil 6'dan, yıllık etkin doz eşdeğeri sonuçlarının, önerilen 0,46 mSv / y güvenlik sınırından daha düşük olduğu açıktır (Tablo 1.).

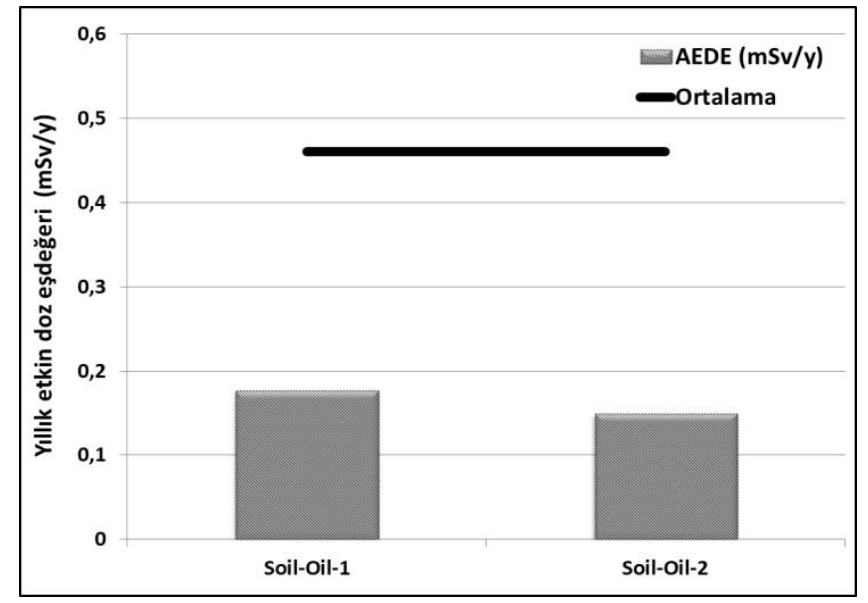

Şekil 6. Yıllık etkin doz eşdeğeri sonuçları

\subsubsection{Radyum Eşdeğer Aktivite İndeksi (Ra $\left.a_{\text {eq }}\right)$}

Radyum eşdeğer aktivite indeksi $\left(\mathrm{Ra}_{\mathrm{eq}}\right),{ }^{40} \mathrm{~K},{ }^{226} \mathrm{Ra}$ ve ${ }^{232} \mathrm{Th}$ doğal radyoaktif elementler içeren maddelerin bu elementleri ile ilişkili radyasyon tehlikelerinin değerlendirilmesi için tanımlanmıştır. Bu indeks aşağıdaki bağıntı kullanılarak hesaplanabilir. [1]:

$$
R a_{e q}=0.077 A_{K}+A_{R a}+1.43 A_{T h}
$$

Burada $A_{K}, A_{R a}$ ve $A_{T h}$ sırasıyla ${ }^{40} \mathrm{~K},{ }^{226} \mathrm{Ra}$ ve ${ }^{232} \mathrm{Th}$ aktivite konsantrasyonlarıdır. Radyum eşdeğer aktivite indeksi sonuçları Şekil 7'de gösterilmiştir. Yağlı toprak örneklerindeki Raeq sonuçları önerilen güvenli limit değer $370 \mathrm{~Bq} / \mathrm{kg}$ 'dan azdır [16]. 


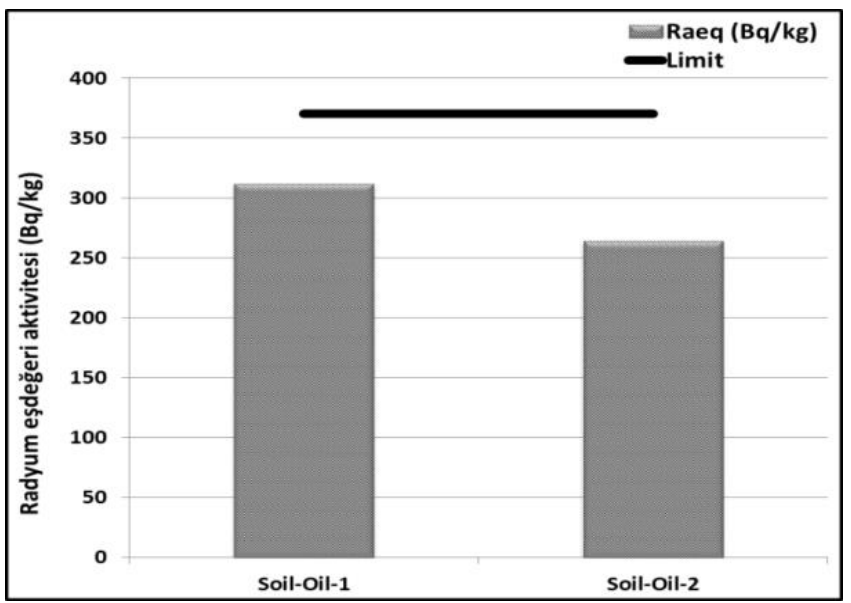

Şekil 7. Radyum eşdeğeri aktivitesi sonuçları

\subsubsection{Dış ve İç Zarar İndeksi $\left(H_{e x}, H_{i n}\right)$}

${ }^{40} \mathrm{~K},{ }^{226} \mathrm{Ra}$ ve ${ }^{232} \mathrm{Th}$ doğal radyonüklidleri içeren taş, toprak gibi çevresel materyallerin sağlık üzerindeki etkileri, dış zarar indeksi $\left(H_{e x}\right)$ adı verilen bir parametre ile değerlendirilir. Radon ve bozunma ürünlerine içsel maruz kalmanın etkileri, iç zarar endeksi $\left(H_{\text {in }}\right)$ ile değerlendirilir. Bu iki parametre radyasyon tehlikesi açısından birim değeri aşmamalıdır. Dış zarar endeksi $\left(\mathrm{H}_{\mathrm{ex}}\right)$ ve iç zarar indeksi $\left(\mathrm{H}_{\text {in }}\right)$ aşağıdaki denklemler kullanılarak hesaplanmıştır [15].

$$
H_{\text {ex }}=\frac{A_{R a}}{370}+\frac{A_{T h}}{259}+\frac{A_{K}}{4810} \quad, \quad H_{\text {in }}=\frac{A_{R a}}{185}+\frac{A_{T h}}{259}+\frac{A_{K}}{4810}
$$

Dış ve iç zarar endeksleri sonuçları Şekil 8'de gösterilmiştir. Elde edilen $H_{\mathrm{ex}}$ değerleri önerilen güvenlik sınırından düşük olduğunu fakat $\mathrm{H}_{\text {in }}$ için elde edilen sonuçlar önerilen güvenlik sınırından yüksek olduğu bulunmuştur.

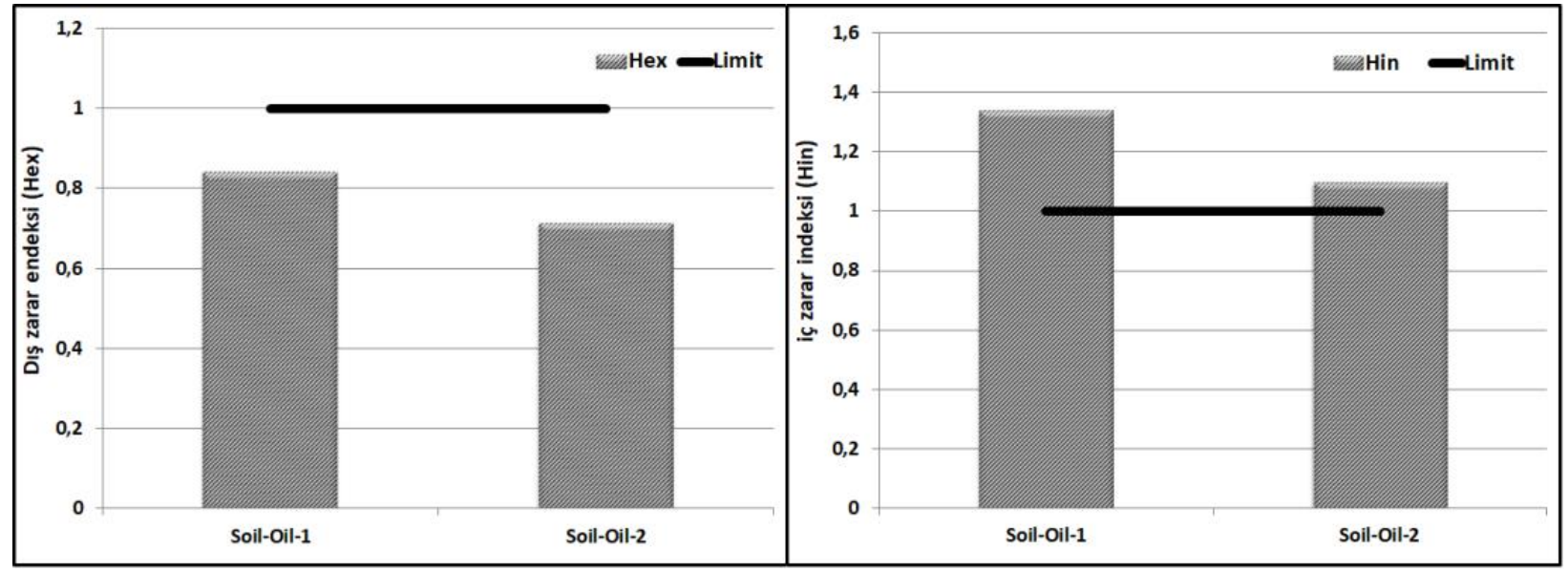

Şekil 8. Dış ve iç zarar endeksleri sonuçları

\section{Sonuç}

Doğal radyoaktivite seviyesini belirlemek için Basra-Irak'taki petrol sahalarından toplanan yağlı toprak örneklerinin doğal yapısında bulunan ${ }^{40} \mathrm{~K},{ }^{226} \mathrm{Ra}$ ve ${ }^{232} \mathrm{Th} \mathrm{K}$ doğal radyonüklitlerinin aktivite konsantrasyonları gama 1şını spektroskopisi sistemi kullanılarak ölçüldü. Bu doğal rayonüklitlerinin yağlı toprak örneklerinin yapısındaki aktivite konsantrasyonları, canlılara ve çevreye olan radyolojik etkilerini değerlendirmek için kullanılan parametrelerin hesaplanmasında faydalıdır. Bu çalışmada absorbe edilen doz oranı (D), yıllık etkili doz eşdeğeri (AEDE), radyum eşdeğeri aktivitesi $\left(\mathrm{Ra}_{\mathrm{eq}}\right)$, dış ve iç zarar indeksleri $\left(\mathrm{H}_{\mathrm{ex}}\right.$ ve $\left.\mathrm{H}_{\mathrm{in}}\right)$ gibi radyolojik zarar parametreleri hesaplanmıştır. Absorbe edilen doz oranı (D) için elde edilen sonuçlar tüm numunelerde önerilen güvenlik sınırı değerini aştığı gözlenmiştir. Yıllık etkin doz eşdeğeri (AEDE), tüm numuneler için önerilen güvenlik sınırının altındadır. Radyum eşdeğeri aktivite $\left(\mathrm{Ra}_{\mathrm{eq}}\right)$ için elde edilen sonuçlar tüm numunelerde önerilen güvenlik limiti değerinin altında olduğu gözlenmiştir. Dış zarar endeksi $\left(\mathrm{H}_{\mathrm{ex}}\right)$ için, tüm numunelerde önerilen güvenlik limiti değerinin altında olduğu gözlenmiştir. Tüm numunelerde iç zarar endeksinin $\left(\mathrm{H}_{\text {in }}\right)$ önerilen güvenlik limiti değerini aşttğı gözlenmiştir. Bu çalışmada üretilen veriler, çalışllan bölgedeki doğal radyoaktiviteseviyesi ve radyolojik parametreler için temel veriler sağlayacak ve bölgede yaşayan insanlar, hayvanlar ve çevre için radyasyondan korunma standartlarının uygulanmasında faydalı olacaktır. 


\section{Kaynakça}

[1]. United Nations Scientific Committee on the Effects of Atomic Radiation UNSCEAR 2000 Report to the General Assembly, with Scientific Annexes. Sources and Effects of Ionizing Radiation, Vol. I: Sources. United Nations Publication, New York, 654s.

[2]. Günoğlu, K., Assessment of lifetime cancer risk due to natural radioactivity in the stones in the Central Anatolia Region, Turkey, Arabian Journal of Geosciences 11: 503, 1-6, 2018

[3]. Al-Masri M. S., Aba, A., Distribution NORM in different oil fields equipment, Appli. Radi. And Isotopes, 63, 4, 457-463, 2005

[4]. İskender A, Ayten Uyanık N, Günoğlu K (2015) Radiation dose estimation: an in vitro measurement for Isparta-Turkey. Int J. Computational Experimental Sci Engineering (IJCESEN) 1-1:1-4

[5]. B. Canbaz, N Füsun Çam, G. Yaprak, O. Candan, 2010. Natural radioactivity (226Ra, 232Th and40K) and assessment of radiological hazards in the Kestanbol granitoid, Turkey, Radiat. Prot. Dosim.141, 192

[6]. Myatt TA, Allen JG, Minegishi T, McCarthy WB, Mac-Intosh DL, McCarthy JF (2010) Assessing exposure to granite countertops - part 1: radiation. J Expo Sci Environ Epidemiol 20:280

[7]. Akkurt I. and Gunoglu, K., 2014. Natural radioactivitymeasurements and radiation dose estimation in some sedimentary rock samples in Turkey. Science and Technology of Nuclear Installations Volume 2014, Article ID 950978

[8]. Yii M, Zaharudin A, Abdul-Kadir I (2009) Distribution of naturally occurring radionuclides activity concentration in East Malaysian marine sediment. Appl Radiat Isot 67(4):630-635

[9]. Abo-Elmagd M., Soliman H.A., Salman Kh.A., El-Masry N.M., (2010). Radiological hazards of TENORM in the wasted petroleum pipes, J. Envron. Radio. 101, 51-54.

[10]. Kadyrzhanov K.K, Tuleushev A.Z, Marabaev Z.N (2005). Radioactive components of scales at the inner surface of pipes in oil fields of Kazakhstan. J Radioanal Nucl Chem 264:413-416.

[11]. Hamlat M.S., Djeffal S., Kadi H. (2001). Assessment of radiation exposures from naturally occurring radioactive materials in the oil and gas industry. Applied Radiation and Isotopes 55, 141-146.

[12]. Omar M, Ali HM, Abu MP (2004) Distribution of radium in oil and gas industry wastes from Malaysia. Appl.Radiat Isot 60:779-782.

[13]. Godoy, J.M., Crux, R.P. (2003). 226Ra and 228Ra in scale and sludge samples and their correlation with the chemical composition. Journal of Environmental Radioactivity 70, 199-206.

[14]. Günay, O. et al. (2019). Natural radioactivity analysis of soil samples from Ganos fault (GF). International Journal of Environmental Science and Technology, 2019, 16.9: 5055-5058.

[15]. Günay, O. (2018). Assessment of lifetime cancer risk from natural radioactivity levels in Kadikoy and Uskudar District of Istanbul. Arabian Journal of Geosciences, 11(24), 782.

[16]. Günay, O., \& Eke, C. (2019). Determination of terrestrial radiation level and radiological parameters of soil samples from Sariyer-Istanbul in Turkey. Arabian Journal of Geosciences, 12(20), 631.

[17]. Akkurt, I., Gunoglu, K., \& Arda, S. S. 2014. Detection efficiency of NaI (Tl) detector in 511-1332 keV energy range. Science and Technology of Nuclear Installations, 2014.

[18]. Beretka J, Mathew PJ 1985. Natural radioactivity of Australian building materials, industrial wastes and by-products. Health Phys 48:87-95

[19]. NEA-OECD, 1979. Exposure to Radiation from Natural Radioactivity in Building Materials. Report by NEA Group of Experts of the Nuclear Energy Agency. OECD, Paris, France. 